\title{
UPPER AND LOWER SOLUTIONS METHOD FOR DIFFERENTIAL INCLUSIONS WITH INTEGRAL BOUNDARY CONDITIONS
}

\author{
MOUFFAK BENCHOHRA AND ABDELGHANI OUAHAB
}

Received 26 July 2004; Revised 8 April 2005; Accepted 12 April 2005

A nonlinear alternative of the Leray-Schauder type for multivalued maps combined with upper and lower solutions is used to investigate the existence of solutions for secondorder differential inclusions with integral boundary conditions.

Copyright (c) 2006 M. Benchohra and A. Ouahab. This is an open access article distributed under the Creative Commons Attribution License, which permits unrestricted use, distribution, and reproduction in any medium, provided the original work is properly cited.

\section{Introduction}

This paper is concerned with the existence of solutions for the second-order boundary value problem:

$$
\begin{gathered}
y^{\prime \prime}(t) \in F(t, y(t)), \quad \text { a.e. } t \in J:=[0,1], \\
y(0)-k_{1} y^{\prime}(0)=\int_{0}^{1} h_{1}(y(s)) d s, \\
y(1)+k_{2} y^{\prime}(1)=\int_{0}^{1} h_{2}(y(s)) d s,
\end{gathered}
$$

where $F: J \times \mathbb{R} \rightarrow \mathscr{P}(\mathbb{R})$ is a compact convex-valued multivalued map, $\mathscr{P}(\mathbb{R})$ is the family of all nonempty subsets of $\mathbb{R}, h_{i}: \mathbb{R} \rightarrow \mathbb{R}(i=1,2)$ are continuous functions, and $k_{i}$ are nonnegative constants.

Boundary value problems with integral boundary conditions constitute a very interesting and important class of problems. They include two-, three-, and multipoint and nonlocal boundary value problems as special cases. For boundary value problems with integral boundary conditions and comments on their importance, we refer the reader to the papers $[9,14,19]$ and the references therein. Moreover, boundary value problems with integral boundary conditions have been studied by a number of authors, for example, $[4,6,16]$. The method of upper and lower solutions has been successfully applied to study the existence of multiple solutions for initial and boundary value problems for 
differential equations with nonlinear conditions. This method has been used only in the context of single-valued differential equations. In this regard, we refer the reader to the monographs by Heikkilä and Lakshmikantham [12] and Ladde et al. [17] and to the recent papers by Rahmat [15] and Rahmat and Bashir [1] in which the first- and secondorder differential equations with integral boundary conditions have been considered. Recently this method has been used for initial and nonlinear boundary conditions of differential inclusions in the papers by Benchohra [2], Benchohra and Ntouyas [3], Frigon [8], Halidias and Papageorgiou [11], and Palmucci and Papalini [20]. In this paper, we will apply the method of upper and lower solutions combined with the nonlinear alternative of Leray-Schauder type [7] to problem (1.1)-(1.3). These results extend to the multivalued case some results from the literature and complement those related to the application of the method of upper and lower solutions to differential inclusions (see $[2,3,8,11,20]$ ).

\section{Preliminaries}

In this section, we introduce notations, definitions, and preliminary facts that will be used in the remainder of this paper. Let $A C^{1}(J, \mathbb{R})$ be the space of differentiable functions $y: J \rightarrow \mathbb{R}$, whose first derivative, $y^{\prime}$, is absolutely continuous.

The property

$$
y \leq \bar{y}, \quad \text { iff } y(t) \leq y(t), \forall t \in J
$$

defines a partial ordering in $A C^{1}(J$, $\mathbb{R})$. If $\alpha, \beta \in A C^{1}(J, \mathbb{R})$ and $\alpha \leq \beta$, we let

$$
[\alpha, \beta]=\left\{y \in A C^{1}(J, \mathbb{R}): \alpha \leq \beta\right\} .
$$

We take $C(J, \mathbb{R})$ to be the Banach space of all continuous functions from $J$ into $\mathbb{R}$ with the norm

$$
\|y\|=\sup \{|y(t)|: 0 \leq t \leq 1\}
$$

and we let $L^{1}(J, \mathbb{R})$ denote the Banach space of functions $y: J \rightarrow \mathbb{R}$ that are Lebesgue integrable with norm

$$
\|y\|_{L^{1}}=\int_{0}^{1}|y(t)| d t
$$

Let $(X,\|\cdot\|)$ be a Banach space. A multivalued map $G: X \rightarrow \mathscr{P}(X)$ has convex (closed) values if $G(x)$ is convex (closed) for all $x \in X$. We say that $G$ is bounded on bounded sets if $G(B)$ is bounded in $X$ for each bounded set $B$ of $X$ (i.e., $\sup _{x \in B}\{\sup \{\|y\|: y \in G(x)\}\}$ $<\infty)$. The map $G$ is upper semicontinuous (u.s.c.) on $X$ if for each $x_{0} \in X$ the set $G\left(x_{0}\right)$ is a nonempty, closed subset of $X$, and if for each open set $N$ of $X$ containing $G\left(x_{0}\right)$, there exists an open neighborhood $M$ of $x_{0}$ such that $G(M) \subseteq N$. Finally, we say that $G$ is completely continuous if $G(B)$ is relatively compact for every bounded subset $B \subseteq X$.

If the multivalued map $G$ is completely continuous with nonempty compact values, then $G$ is u.s.c. if and only if $G$ has a closed graph (i.e., $x_{n} \rightarrow x_{*}, y_{n} \rightarrow y_{*}, y_{n} \in G\left(x_{n}\right)$ imply $\left.y_{*} \in G\left(x_{*}\right)\right)$. We say that $G$ has a fixed point if there exists $x \in X$ such that $x \in G(x)$. 
In what follows, $\mathscr{P}(X)=\{Y \subset X: Y \neq \varnothing\}, \mathscr{P}_{\mathrm{cl}}(X)=\{Y \in \mathscr{P}(X): Y$ closed $\}, \mathscr{P}_{b}(X)=$ $\{Y \in \mathscr{P}(X): Y$ bounded $\}, \mathscr{P}_{\mathrm{cp}}(X)=\{Y \in \mathscr{P}(X): Y$ compact $\}$, and $\mathscr{P}_{c, \mathrm{cp}}(X)=\mathscr{P}_{c}(X) \cap$ $\mathscr{P}_{\mathrm{cp}}(X)$. A multivalued map $G: J \rightarrow \mathscr{P}_{\mathrm{cl}}(\mathbb{R})$ is said to be measurable if for each $x \in \mathbb{R}$ the function $Y: J \rightarrow \mathbb{R}$ defined by

$$
Y(t)=d(x, G(t))=\inf \{|x-z|: z \in G(t)\}
$$

is measurable. For more details on multivalued maps, see the books of Deimling [5], Górniewicz [10], and $\mathrm{Hu}$ and Papageorgiou [13].

Definition 2.1. The multivalued map $F: J \times \mathbb{R} \rightarrow \mathscr{P}(\mathbb{R})$ is an $L^{1}$-Carathéodory if

(i) $t \mapsto F(t, y)$ is measurable for each $y \in \mathbb{R}$;

(ii) $y \mapsto F(t, y)$ is u.s.c. for a.a. $t \in J$;

(iii) for each $q>0$, there exists $\phi_{q} \in L^{1}\left(J, \mathbb{R}_{+}\right)$such that

$$
\|F(t, y)\|_{\mathscr{P}}=\sup \{|v|: v \in F(t, y)\} \leq \phi_{q}(t) \quad \forall|y| \leq q \text { and for a.a. } t \in J .
$$

Definition 2.2. A function $y \in A C^{1}([0,1], \mathbb{R})$ is said to be a solution of (1.1)-(1.3) if there exists $v \in L^{1}(J, \mathbb{R})$ with $v(t) \in F(t, y(t))$ for a.e. $t \in J$ such that $y$ satisfies the differential equation $y^{\prime \prime}(t)=v(t)$ a.e. on $J$ and the conditions (1.2) and (1.3).

For any $y \in C([0,1], \mathbb{R})$, we define the set

$$
S_{F(y)}=\left\{v \in L^{1}(J, \mathbb{R}): v(t) \in F(t, y(t)) \text { for a.e. } t \in J\right\} .
$$

This is known as the set of selection functions.

Definition 2.3. A function $\alpha \in A C^{1}([0,1], \mathbb{R})$ is said to be a lower solution of (1.1)-(1.3) if there exists $v_{1} \in L^{1}(J, \mathbb{R})$ such that $v_{1}(t) \in F(t, \alpha(t))$ a.e. on $J, \alpha^{\prime \prime}(t) \geq v_{1}(t)$ a.e. on $J$, $\alpha(0)-k_{1} \alpha^{\prime}(0) \leq \int_{0}^{1} h_{1}(\alpha(s)) d s$, and $\alpha(1)+k_{2} \alpha^{\prime}(1) \leq \int_{0}^{1} h_{2}(\alpha(s)) d s$. Similarly, a function $\beta \in A C^{1}([0,1], \mathbb{R})$ is said to be an upper solution of $(1.1)-(1.3)$ if there exists $v_{2} \in L^{1}(J, \mathbb{R})$ such that $v_{2}(t) \in F(t, \beta(t))$ a.e. on $J, \beta^{\prime \prime}(t) \leq v_{2}(t)$ a.e. on $J, \beta(0)-k_{1} \beta^{\prime}(0) \geq \int_{0}^{1} h_{1}(\beta(s)) d s$, and $\beta(1)+k_{2} \beta^{\prime}(1) \geq \int_{0}^{1} h_{2}(\beta(s)) d s$.

The following lemma is crucial in the proof of our main theorem.

Lemma 2.4 [18]. Let $X$ be a Banach space. Let $F:[0, b] \times X \rightarrow \mathscr{P}_{\mathrm{cp}, c}(X)$ be an $L^{1}$-Carathéodory multivalued map and let $\Gamma$ be a linear continuous mapping from $L^{1}([0, b], X)$ to $C([0, b], X)$, then the operator

$$
\Gamma \circ S_{F}: C([0, b], X) \longrightarrow \mathscr{P}_{\mathrm{cp}, c}(C([0, b], X)), y \longmapsto\left(\Gamma \circ S_{F}\right)(y):=\Gamma\left(S_{F(y)}\right)
$$

is a closed graph operator in $C([0, b], X) \times C([0, b], X)$.

\section{Main result}

We are now in a position to state and prove our existence result for the problem (1.1)(1.3). We first list the following hypotheses:

$(\mathrm{H} 1) F: J \times \mathbb{R} \rightarrow \mathscr{P}_{\mathrm{cp}, c}(\mathbb{R})$ is an $L^{1}$-Carathéodory multivalued map; 
4 Differential inclusions with integral boundary conditions

(H2) there exist $\alpha$ and $\beta \in A C^{1}([0,1], \mathbb{R})$, lower and upper solutions, respectively, for the problem (1.1)-(1.3) such that $\alpha \leq \beta$;

(H3) $h_{i}$ are continuous and nondecreasing functions, $i=1,2$.

Theorem 3.1. Assume that hypotheses (H1)-(H3) hold. Then the problem (1.1)-(1.3) has at least one solution y such that

$$
\alpha(t) \leq y(t) \leq \beta(t) \quad \forall t \in J
$$

Proof. We will transform the problem (1.1)-(1.3) into a fixed point problem. Consider the modified problem

$$
\begin{aligned}
& y^{\prime \prime}(t) \in F_{1}(t, y(t)), \quad \text { a.e. } t \in J, \\
& y(0)-k_{1} y^{\prime}(0)=\int_{0}^{1} L_{1}(y(s)) d s, \\
& y(1)+k_{2} y^{\prime}(1)=\int_{0}^{1} L_{2}(y(s)) d s,
\end{aligned}
$$

where

$$
\begin{gathered}
F_{1}(t, y)= \begin{cases}F(t, \beta(t))+\frac{y-\beta(t)}{1+|y-\beta(t)|}, & \text { if } y>\beta(t), \\
F(t, y), & \text { if } \alpha(t) \leq y \leq \beta(t), \\
F(t, \alpha(t))+\frac{y-\alpha(t)}{1+|y-\alpha(t)|}, & \text { if } y<\alpha(t),\end{cases} \\
L_{i}(y)= \begin{cases}h_{i}(\beta(t)), & \text { if } y>\beta(t), \\
h_{i}(y), & \text { if } \alpha(t) \leq y \leq \beta(t), \\
h_{i}(\alpha(t)), & \text { if } y<\alpha(t),\end{cases}
\end{gathered}
$$

for every fixed $t \in J$. A solution to (3.2)-(3.4) is a fixed point of the operator $N: C(J, \mathbb{R}) \rightarrow$ $\mathscr{P}(C(J, \mathbb{R}))$ defined by

$$
N(y)=\left\{h \in C(J, \mathbb{R}): h(t)=p(t)+\int_{0}^{1} G(t, s) g(s) d s, g \in \widetilde{S}_{F_{1}(y)}^{1}\right\},
$$

where

$$
\begin{aligned}
\tilde{S}_{F_{1}(y)}^{1} & =\left\{v \in S_{F_{1}(y)}^{1}: v(t) \leq v_{1}(t) \text { a.e. on } A_{1}, v(t) \geq v_{2}(t) \text { a.e. on } A_{2}\right\}, \\
S_{F_{1}(y)}^{1} & =\left\{v \in L^{1}(J, \mathbb{R}): v(t) \in F_{1}(t, y(t)) \text { for a.e. } t \in J\right\}, \\
A_{1} & =\{t \in J: y(t)<\alpha(t) \leq \beta(t)\}, \quad A_{2}=\{t \in J: \alpha(t) \leq \beta(t)<y(t)\}, \\
p(t) & =\frac{1}{1+k_{1}+k_{2}}\left\{\left(1-t+k_{2}\right) \int_{0}^{1} L_{1}(y(s)) d s+\left(k_{1}+t\right) \int_{0}^{1} L_{2}(y(s)) d s\right\},
\end{aligned}
$$


and $G(\cdot, \cdot)$ is the Green function of the problem

$$
\begin{aligned}
& x^{\prime \prime}(t)=0, \quad t \in J, \\
& x(0)-k_{1} x^{\prime}(0)=0, \\
& x(1)+k_{2} x^{\prime}(1)=0,
\end{aligned}
$$

where

$$
G(t, s)=\frac{-1}{k_{1}+k_{2}+1} \begin{cases}\left(k_{1}+t\right)\left(1-s+k_{2}\right), & 0 \leq t<s \leq 1 \\ \left(k_{1}+s\right)\left(1-t+k_{2}\right), & 0 \leq s<t \leq 1\end{cases}
$$

Remark 3.2. (i) For each $y \in C(J, \mathbb{R})$, the set $S_{F(y)}^{1}$ is nonempty (see Lasota and Opial [18]).

(ii) For each $y \in C(J, \mathbb{R})$, the set $\widetilde{S}_{F_{1}(y)}^{1}$ is nonempty. In fact, (i) implies that there exists $v \in S_{F(y)}^{1}$, so we set

$$
w=v_{1} \chi_{A_{1}}+v_{2} \chi_{A_{2}}+v \chi_{A_{3}}
$$

where

$$
A_{3}=\{t \in J: \alpha(t) \leq y(t) \leq \beta(t)\}
$$

Then, by the decomposability, $w \in \widetilde{S}_{F_{1}(y)}^{1}$.

Remark 3.3. Notice that $F_{1}$ is an $L^{1}$-Carathéodory multivalued map with compact convex values and there exists $\phi \in L^{1}(J, \mathbb{R})$ such that

$$
\left\|F_{1}(t, y)\right\| \leq \phi(t)+1
$$

In order to apply the nonlinear alternative of Leray-Schauder type, we first show that $N$ is completely continuous with convex values. The proof will be given in several steps.

Step 3.4. $N(y)$ is convex for each $y \in C(J, \mathbb{R})$.

Indeed, if $h_{1}, h_{2}$ belong to $N(y)$, then there exist $g_{1}, g_{2} \in \widetilde{S}_{F_{1}(y)}^{1}$ such that for each $t \in J$, we have

$$
h_{i}(t)=p(t)+\int_{0}^{1} G(t, s) g_{i}(s) d s, \quad i=1,2 .
$$

Let $0 \leq d \leq 1$. Then, for each $t \in J$, we have

$$
\left(d h_{1}+(1-d) h_{2}\right)(t)=p(t)+\int_{0}^{t} G(t, s)\left[d g_{1}(s)+(1-d) g_{2}(s)\right] d s .
$$

Since $\widetilde{S}_{F_{1}(y)}^{1}$ is convex (because $F_{1}$ has convex values), we see that

$$
d h_{1}+(1-d) h_{2} \in N(y)
$$


6 Differential inclusions with integral boundary conditions

Step 3.5. $N$ maps bounded sets into bounded sets in $C(J, \mathbb{R})$.

It suffices to show that for each $q>0$, there exists a positive constant $\ell$ such that for each $y \in B_{q}=\left\{y \in C(J, \mathbb{R}):\|y\|_{\infty} \leq q\right\}$, we have

$$
\|N(y)\|_{\mathscr{P}}:=\sup \left\{\|h\|_{\infty}: h \in N(y)\right\} \leq \ell .
$$

Let $y \in B_{q}$ and $h \in N(y)$; then there exists $g \in \widetilde{S}_{F_{1}(y)}^{1}$ such that for each $t \in J$, we have

$$
h(t)=p(t)+\int_{0}^{1} G(t, s) g(s) d s
$$

By (H1), for each $t \in J$, we have

$$
\begin{aligned}
|h(t)| & \leq|p(t)|+\int_{0}^{1}|G(t, s)||g(s)| d s \\
& \leq 2 \bar{p}+\frac{\left(k_{1}+1\right)\left(1+k_{2}\right)}{k_{1}+k_{2}+1} \int_{0}^{1}(\phi(s)+1) d s
\end{aligned}
$$

where

$$
\bar{p}=\frac{\max \left(1+k_{2}, k_{1}+1\right)}{1+k_{1}+k_{2}}\left(\max \left(h_{i}\left(\min _{t \in[0,1]}|\alpha(t)|\right), h_{i}\left(\max _{t \in[0,1]}|\beta(t)|\right), i=1,2\right)\right) .
$$

Step 3.6. $N$ maps bounded sets into equicontinuous sets in $C(J, \mathbb{R})$.

Let $u_{1}, u_{2} \in J, u_{1}<u_{2}$, and let $B_{q}$ be a bounded set in $C(J, \mathbb{R})$ as in Step 3.5. Let $y \in B_{q}$ and $h \in N(y)$; then there exists $g \in \widetilde{S}_{F_{1}(y)}^{1}$ such that for each $t \in J$, we have

$$
\begin{aligned}
\left|h\left(u_{2}\right)-h\left(u_{1}\right)\right| \leq & \left|p\left(u_{2}\right)-p\left(u_{1}\right)\right|+\int_{0}^{1}\left|G\left(u_{2}, s\right)-G\left(u_{1}, s\right)\right||g(s)| d s \\
\leq & \left|p\left(u_{2}\right)-p\left(u_{1}\right)\right|+\int_{0}^{1}\left|G\left(u_{2}, s\right)-G\left(u_{1}, s\right)\right| \phi(s) d s \\
& +\int_{0}^{1}\left|G\left(u_{2}, s\right)-G\left(u_{1}, s\right)\right| d s,
\end{aligned}
$$

where

$$
\begin{aligned}
\left|p\left(u_{2}\right)-p\left(u_{1}\right)\right| & \leq \frac{\left|u_{2}-u_{1}\right|}{1+k_{1}+k_{2}} \int_{0}^{1}\left|L_{1}(y(s))\right| d s+\frac{\left|u_{2}-u_{1}\right|}{1+k_{1}+k_{2}} \int_{0}^{1}\left|L_{2}(y(s))\right| d s \\
& \leq 2 \frac{\left|u_{2}-u_{1}\right|}{1+k_{1}+k_{2}}\left(\max \left(h_{i}\left(\min _{t \in[0,1]}|\alpha(t)|\right), h_{i}\left(\max _{t \in[0,1]}|\beta(t)|\right), i=1,2\right)\right) .
\end{aligned}
$$

As $u_{2} \rightarrow u_{1},\left|h\left(u_{2}\right)-h\left(u_{1}\right)\right|$ tends to zero.

As a consequence of Steps 3.4-3.6, together with the Arzela-Ascoli theorem, we can conclude that $N: C(J, \mathbb{R}) \rightarrow \mathscr{P}_{\mathrm{cp}}(C(J, \mathbb{R}))$ is a completely continuous multivalued map. 
Step 3.7. $N$ has a closed graph.

Let $y_{n} \rightarrow y_{*}, h_{n} \in N\left(y_{n}\right)$, and $h_{n} \rightarrow h_{*}$. We will prove that $h_{*} \in N\left(y_{*}\right)$. Now $h_{n} \in$ $N\left(y_{n}\right)$ implies that there exists $g_{n} \in \widetilde{S}_{F_{1}\left(y_{n}\right)}^{1}$ such that for each $t \in J$,

$$
h_{n}(t)=p_{n}(t)+\int_{0}^{1} G(t, s) g_{n}(s) d s
$$

where

$$
p_{n}(t)=\frac{1}{1+k_{1}+k_{2}}\left[\left(1-t+k_{2}\right) \int_{0}^{1} L_{1}\left(y_{n}(s)\right) d s+\left(k_{1}+t\right) \int_{0}^{1} L_{2}\left(y_{n}(s)\right) d s\right] .
$$

We must prove that there exists $g_{*} \in \widetilde{S}_{F_{1}\left(y_{*}\right)}^{1}$ such that for each $t \in J$,

$$
h_{*}(t)=p_{*}(t)+\int_{0}^{1} G(t, s) g_{*}(s) d s
$$

where

$$
p_{*}(t)=\frac{1}{1+k_{1}+k_{2}}\left[\left(1-t+k_{2}\right) \int_{0}^{1} L_{1}\left(y_{*}(s)\right) d s+\left(k_{1}+t\right) \int_{0}^{1} L_{2}\left(y_{*}(s)\right) d s\right] .
$$

Since $p$ is continuous, we have

$$
\left\|\left(h_{n}-p_{n}\right)-\left(h_{*}-p_{*}\right)\right\|_{\infty} \longrightarrow 0, \quad \text { as } n \longrightarrow \infty .
$$

Consider the continuous linear operator

$$
\begin{gathered}
\Gamma: L^{1}(J, \mathbb{R}) \longrightarrow C(J, \mathbb{R}), \\
g \longmapsto(\Gamma g)(t)=\int_{0}^{1} G(t, s) g(s) d s .
\end{gathered}
$$

From Lemma 2.4, it follows that $\Gamma \circ \widetilde{S}_{F_{1}(y)}^{1}$ is a closed graph operator. Moreover, we have that

$$
h_{n}(t)-p_{n}(t) \in \Gamma\left(\widetilde{S}_{F_{1}\left(y_{n}\right)}^{1}\right) .
$$

Since $y_{n} \rightarrow y_{*}$, it follows from Lemma 2.4 that

$$
h_{*}(t)-p_{*}(t)=\int_{0}^{1} G(t, s) g_{*}(s) d s
$$

for some $g_{*} \in \widetilde{S}_{F_{1}\left(y_{*}\right)}^{1}$.

Step 3.8. A priori bounds on solutions exist.

Let $y \in \lambda N(y)$ for some $\lambda \in(0,1)$. Then there exists $g \in \widetilde{S}_{F_{1}, y}$ such that

$$
y(t)=\lambda\left[p(t)+\int_{0}^{1} G(t, s) g(s) d s\right] .
$$


8 Differential inclusions with integral boundary conditions

By Remark 3.3, for each $t \in J$, we have

$$
\begin{aligned}
|y(t)| & \leq|p(t)|+\int_{0}^{1}|G(t, s)||g(s)| d s \\
& \leq 2 \bar{p}+\frac{\left(k_{1}+1\right)\left(1+k_{2}\right)}{1+k_{1}+k_{2}} \int_{0}^{1} \phi(t) d s+\frac{\left(k_{1}+1\right)\left(1+k_{2}\right)}{1+k_{1}+k_{2}} .
\end{aligned}
$$

Thus

$$
\|y\|_{\infty} \leq 2 \bar{p}+\frac{\left(k_{1}+1\right)\left(1+k_{2}\right)}{1+k_{1}+k_{2}} \int_{0}^{1} \phi(t) d s+\frac{\left(k_{1}+1\right)\left(1+k_{2}\right)}{1+k_{1}+k_{2}}:=\ell_{*} .
$$

Set

$$
U=\left\{y \in C([0,1], \mathbb{R}):\|y\|_{\infty}<\ell_{*}+1\right\}
$$

and consider the operator $N$ defined on $\bar{U}$. From the choice of $U$, there is no $y \in \partial U$ such that $y \in \lambda N(y)$ for some $\lambda \in(0,1)$. As a consequence of the nonlinear alternative of Leray-Schauder type [7], we deduce that $N$ has a fixed point $y$ in $\bar{U}$, that is, a solution of the problem (3.2)-(3.4).

Step 3.9. The solution $y$ of (3.2)-(3.4) satisfies

$$
\alpha(t) \leq y(t) \leq \beta(t) \quad \forall t \in J .
$$

Let $y$ be a solution to (3.2)-(3.4). We will show that

$$
\alpha(t) \leq y(t) \quad \forall t \in J .
$$

Suppose this is not the case. Let $r(t)=\alpha(t)-y(t)$, then the function $r$ has positive maximum at some $t_{0} \in[0,1]$, such that $r\left(t_{0}\right)=\max r(t)$, then

$$
r\left(t_{0}\right)>0, \quad r^{\prime}\left(t_{0}\right)=0, \quad r^{\prime \prime}\left(t_{0}\right) \leq 0 .
$$

If $t_{0} \in(0,1)$, then there exists $c_{1} \in[0,1]$ such that

$$
r(t)>0 \quad \forall t \in\left[c_{1}, t_{0}\right] .
$$

In view of the definition of $F_{1}$, we have

$$
y^{\prime \prime}(t) \in F(t, \alpha(t))+\frac{y(t)-\alpha(t)}{1+|y(t)-\alpha(t)|} \quad \text { on }\left[c_{1}, t_{0}\right] .
$$

Thus, there exists $v(t) \in F(t, \alpha(t))$ a.e. on $\left[c_{1}, t_{0}\right]$ with $v(t) \geq v_{1}(t)$ a.e. on $\left[c_{1}, t_{0}\right]$ such that

$$
y^{\prime \prime}(t)=v(t)+\frac{y(t)-\alpha(t)}{1+|y(t)-\alpha(t)|}, \quad \text { a.e on }\left[c_{1}, t_{0}\right] .
$$

Using the fact that $\alpha$ is a lower solution to (1.1)-(1.3), we have

$$
\alpha^{\prime \prime}(t)-y^{\prime \prime}(t)=\alpha^{\prime \prime}(t)-v(t)-\frac{y(t)-\alpha(t)}{1+|y(t)-\alpha(t)|}>0 \quad \text { on }\left[c_{1}, t_{0}\right]
$$


Hence

$$
0 \geq \alpha^{\prime \prime}\left(t_{0}\right)-y^{\prime \prime}\left(t_{0}\right)>0
$$

which is a contradiction. If $t_{0}=0$,

$$
0<r(0)=\alpha(0)-k_{1} y^{\prime}(0)-\int_{0}^{1} L_{1}(y(s)) d s .
$$

By definition of the lower solution, we have

$$
\begin{aligned}
0 & <k_{1} \alpha^{\prime}(0)-k_{1} y^{\prime}(0)+\int_{0}^{1}\left[h_{1}(\alpha(s))-L_{1}(y(s))\right] d s \\
& =k_{1} r^{\prime}(0)+\int_{0}^{1}\left[h_{1}(\alpha(s))-L_{1}(y(s))\right] d s \\
& \leq \int_{0}^{1}\left[h_{1}(\alpha(s))-L_{1}(y(s))\right] d s \\
& \leq \max _{t \in[0,1]}\left(h_{1}(\alpha(t))-L_{1}(y(t))\right) .
\end{aligned}
$$

Let $t_{*} \in[0,1]$ such that

$$
\max _{t \in[0,1]}\left(h_{1}(\alpha(t))-L_{1}(y(t))\right)=h_{1}\left(\alpha\left(t_{*}\right)\right)-L_{1}\left(y\left(t_{*}\right)\right) .
$$

If $\alpha\left(t_{*}\right)>y\left(t_{*}\right)$, we have $L_{1}\left(y\left(t_{*}\right)\right)=h_{1}\left(\alpha\left(t_{*}\right)\right)$, which implies $0<r(0) \leq 0$; this is a contradiction.

If $y\left(t_{*}\right)>\beta\left(t_{*}\right)$, then $L_{1}\left(y\left(t_{*}\right)\right)=h_{1}\left(\beta\left(t_{*}\right)\right) \geq h_{1}\left(\alpha\left(t_{*}\right)\right)$ and again $0<r(0) \leq 0$; another contradiction. Similarly, if $t_{0}=1$, we get a contradiction. Thus $\alpha(t) \leq y(t), t \in$ $[0,1]$. Similarly, we can show that $y(t) \leq \beta(t) t \in[0,1]$.

This shows that the problem (3.2)-(3.4) has a solution in the interval $[\alpha, \beta]$, which is a solution of the problem (1.1)-(1.3).

\section{Acknowledgment}

The authors are thankful to the referee for many suggestions for the improvement of this paper.

\section{References}

[1] B. Ahmad, R. A. Khan, and S. Sivasundaram, Generalized quasilinearization method for a first order differential equation with integral boundary condition, Dynamics of Continuous, Discrete \& Impulsive Systems. Series A. Mathematical Analysis 12 (2005), no. 2, 289-296.

[2] M. Benchohra, Upper and lower solutions method for second order differential inclusions, Dynamic Systems and Applications 11 (2002), no. 1, 13-20.

[3] M. Benchohra and S. K. Ntouyas, The lower and upper solutions method for first order differential inclusions with nonlinear boundary conditions, JIPAM. Journal of Inequalities in Pure and Applied Mathematics 3 (2002), no. 1, Article 14, 8 pp.

[4] S. A. Brykalov, A second-order nonlinear problem with two-point and integral boundary conditions, Georgian Mathematical Journal 1 (1994), no. 3, 243-249. 
[5] K. Deimling, Multivalued Differential Equations, de Gruyter Series in Nonlinear Analysis and Applications, vol. 1, Walter de Gruyter, Berlin, 1992.

[6] M. Denche and A. L. Marhoune, High-order mixed-type differential equations with weighted integral boundary conditions, Electronic Journal of Differential Equations 2000 (2000), no. 60, $1-10$.

[7] J. Dugundji and A. Granas, Fixed Point Theory. I, Monografie Matematyczne, vol. 61, Państwowe Wydawnictwo Naukowe (PWN), Warsaw, 1982.

[8] M. Frigon, Application de la théorie de la transversalité topologique à des problèmes non linéaires pour des équations différentielles ordinaires [Applications of the theory of topological transversality to nonlinear problems for ordinary differential equations], Dissertationes Mathematicae (Rozprawy Matematyczne) 296 (1990), 75 pp. (French).

[9] J. M. Gallardo, Second-order differential operators with integral boundary conditions and generation of analytic semigroups, The Rocky Mountain Journal of Mathematics 30 (2000), no. 4, $1265-1291$.

[10] L. Górniewicz, Topological Fixed Point Theory of Multivalued Mappings, Mathematics and Its Applications, vol. 495, Kluwer Academic, Dordrecht, 1999.

[11] N. Halidias and N. S. Papageorgiou, Second order multivalued boundary value problems, Archivum Mathematicum (Brno) 34 (1998), no. 2, 267-284.

[12] S. Heikkilä and V. Lakshmikantham, Monotone Iterative Techniques for Discontinuous Nonlinear Differential Equations, Monographs and Textbooks in Pure and Applied Mathematics, vol. 181, Marcel Dekker, New York, 1994.

[13] Sh. Hu and N. S. Papageorgiou, Handbook of Multivalued Analysis. Vol. I. Theory, Mathematics and Its Applications, vol. 419, Kluwer Academic, Dordrecht, 1997.

[14] G. L. Karakostas and P. Ch. Tsamatos, Multiple positive solutions of some Fredholm integral equations arisen from nonlocal boundary-value problems, Electronic Journal of Differential Equations 2002 (2002), no. 30, 1-17.

[15] R. A. Khan, The generalized method of quasilinearization and nonlinear boundary value problems with integral boundary conditions, Electronic Journal of Qualitative Theory of Differential Equations 2003 (2003), no. 19, 1-15.

[16] A. M. Krall, The adjoint of a differential operator with integral boundary conditions, Proceedings of the American Mathematical Society 16 (1965), 738-742.

[17] G. S. Ladde, V. Lakshmikantham, and A. S. Vatsala, Monotone Iterative Techniques for Nonlinear Differential Equations, Monographs, Advanced Texts and Surveys in Pure and Applied Mathematics, 27, Pitman, Massachusetts, 1985.

[18] A. Lasota and Z. Opial, An application of the Kakutani-Ky Fan theorem in the theory of ordinary differential equations, Bulletin de l'Académie Polonaise des Sciences. Série des Sciences Mathématiques, Astronomiques et Physiques 13 (1965), 781-786.

[19] A. Lomtatidze and L. Malaguti, On a nonlocal boundary value problem for second order nonlinear singular differential equations, Georgian Mathematical Journal 7 (2000), no. 1, 133-154.

[20] M. Palmucci and F. Papalini, Periodic and boundary value problems for second order differential inclusions, Journal of Applied Mathematics and Stochastic Analysis 14 (2001), no. 2, 161-182.

Mouffak Benchohra: Department of Mathematics, University of Sidi Bel Abbes, BP 89 22000,

Sidi Bel Abbes, Algeria

E-mail address: benchohra@univ-sba.dz

Abdelghani Ouahab: Department of Mathematics, University of Sidi Bel Abbes, BP 89 22000,

Sidi Bel Abbes, Algeria

E-mail address: ouahab@univ-sba.dz 


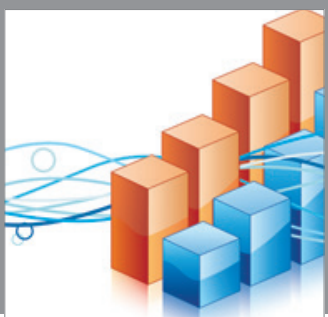

Advances in

Operations Research

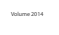

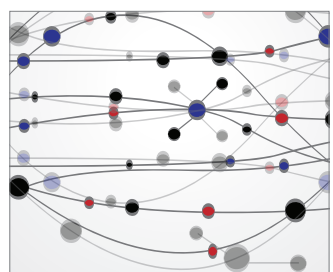

\section{The Scientific} World Journal
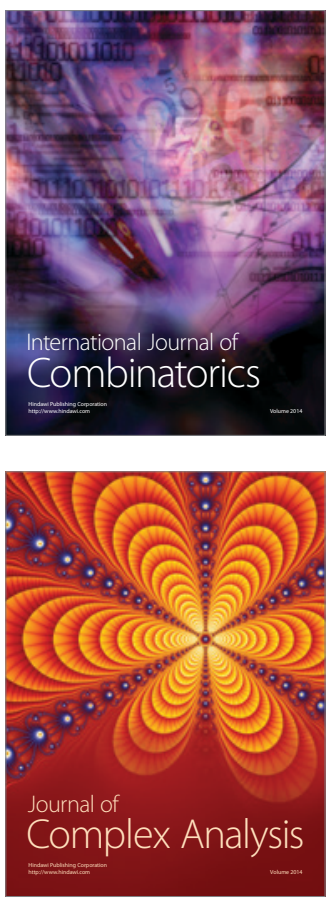

International Journal of

Mathematics and

Mathematical

Sciences
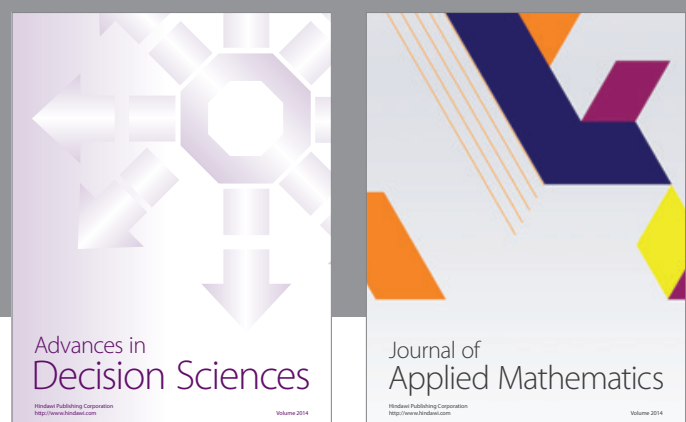

Journal of

Applied Mathematics
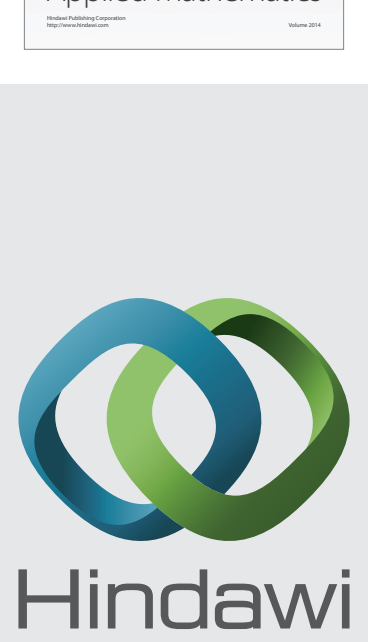

Submit your manuscripts at http://www.hindawi.com
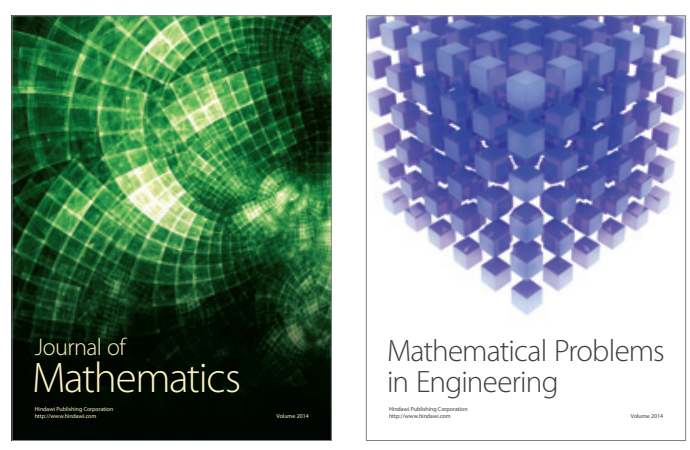

Mathematical Problems in Engineering
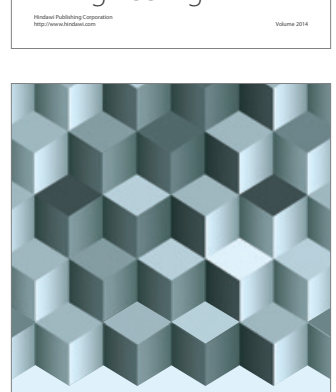

Journal of

Function Spaces
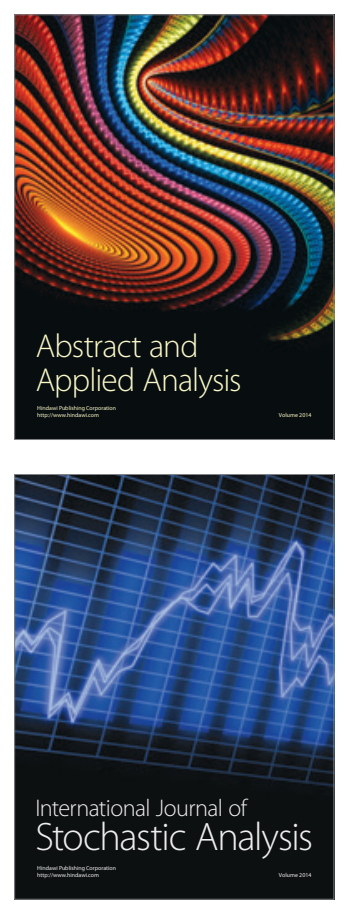

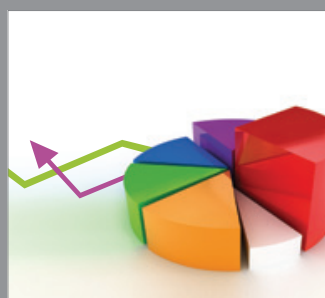

ournal of

Probability and Statistics

Promensencen
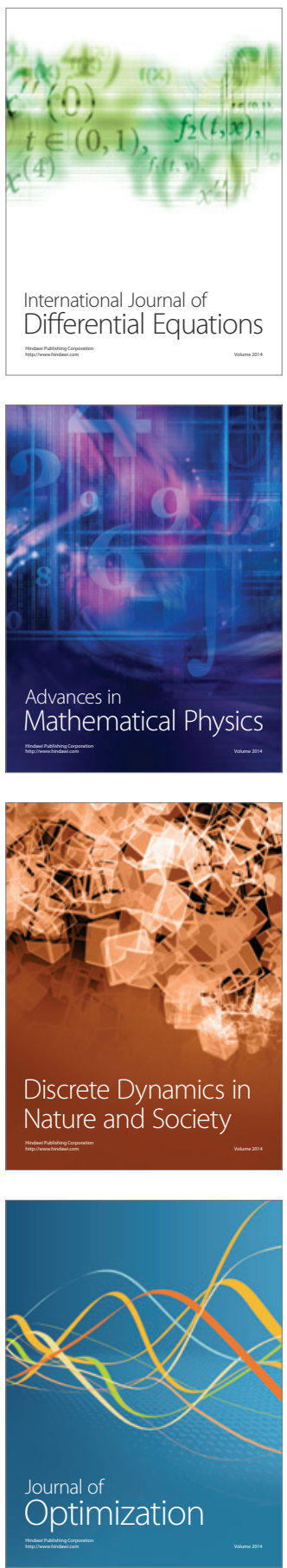